\title{
Influência do valor da CCS e CBT sobre o valor final pago por litro de leite
}

\author{
Influence of the value of CCS and CBT on the final value paid per liter of milk \\ Influencia del valor de CSS y CBT en el monto final pagado por litro de leche
}

\section{Resumo}

Objetivou-se avaliar o efeito das penalizações ou bonificações referentes à contagem bacteriana total (CBT) e contagem de células somáticas (CCS) do leite sobre o valor final pago pelo litro de leite em uma propriedade em Minas Gerais. Foram coletados os dados mensais referentes aos valores de CBT e CCS obtidos após análise do leite e as informações referentes ao valor pago por litro, entregue entre os meses de outubro de 2019 a junho de 2020. Dos 9 meses analisados, a propriedade não apresentou alterações sobre o valor de CBT, permanecendo com uma média geral de 7(x1000) UFC/ml, mantendo-se abaixo da média exigida pela IN 76 que permite um valor máximo de 300(x1000) $\mathrm{UFC} / \mathrm{ml}$. O produtor foi bonificado com $\mathrm{R} \$ 0,04$ por litro, arrecadando no final do período um valor de $\mathrm{R} \$ 1.877,00$. O valor médio da CCS no período estudado foi de 464,3(x1000) CS/ml, entretanto as análises de outubro de 2019 à fevereiro de 2020 apontaram aumento no valor CCS, resultando em uma média de 576,2(x1000) CS/ml, permanecendo fora dos padrões máximos exigidos pela IN 76 de 500(x1000) CS/ml, resultando em penalização ao produtor em R $\$ 0,06$ por litro a penalização refletiu em uma redução de $5 \%$ no valor final pago pelo litro de leite. Após adoção de práticas corretivas e preventivas houve redução da no valor de CCS da fazenda. Desta forma, é possível concluir que a assistência técnica é de suma importância para assessorar o produtor no melhor desenvolvimento da atividade leiteira maximizando o retorno financeiro da propriedade.

Palavras-chave: Agricultura familiar; Bovinocultura de leite; Qualidade do leite; Rentabilidade.

\begin{abstract}
This study aimed to evaluate the effect of penalties or bonuses related to total bacterial count (TBC) and somatic cell cout (CCS) of milk on the final amount paid for liter of milk in a property in Minas Gerais. Monthly data were collected regarding the CBT and CCS values obtained after analyzing the milk and the information regarding the amount paid per liter, delivered between the months of October 2019 to June 2020. Of the 9 months analyzed, the property did not show changes in the CBT value, remaining with na overall average of 7 (x1000) UFC/ml, remaining below the average required by IN 76, which allows a maximum value of 300(x1000) CFU/ml. The producer received a subsidy with $\mathrm{R} \$ 0.04$ per liter, raising at the end of the period an amount of $\mathrm{R} \$ 1,877.00$. The mean value of CCS in the study period was 464.3(x1000) CS/ml, however the analyzes from October 2019 to February 2020 showed an increase in the CCS value, resulting in an average of $576.2(\mathrm{x} 1000) \mathrm{CS} / \mathrm{ml}$, remaining outside from maximum standards required by IN 76 of $500(x 1000) \mathrm{CS} / \mathrm{ml}$, resulting in a penalty to the producer of R 0.06 per liter. The penalty reflected in a $5 \%$ reduction in the final amount paid for the liter of milk. After the adoption of corrective and
\end{abstract}


preventive practices, there was a reduction in the value of the farm's CCS. Thus, it is possible to conclude that technical assistance is of paramount importance to advise the producesr on the best development of the dairy activity, maximizing the property's financial return.

Keywords: Family farming; Dairy cattle farming; Milk quality; Profitability.

\section{Resumen}

Este estudio tuvo como objetivo evaluar el efecto de las sanciones o bonificaciones relacionadas con el recuento bacteriano total (TCC) y el recuento de células somáticas (CCS) de la leche sobre el monto final pagado por un litro de leche em una propriedad en Minas Gerais. Se recolectaron datos mensuales sobre los valores de CBT y CCS obtenidos luego de analizar la leche e información sobre el monto pagado por litro, entregado entre los meses de octubre de 2019 a junio de 2020. De los 9 meses analizados, la propriedad no mostró câmbios en el valor de CBT, quedando com un promedio general de $7(x 1000) \mathrm{UFC} / \mathrm{ml}$, quedando por debajo del prometido requerido por IN 76, que permite un valor máximo de 300 (x1000) UFC/ml. El productor recibió um bono de R \$ 0,04 por litro, ganando al final del período un monto de R \$1.877,00. El valor médio de CCS en el período estudiado fue de 464,3(x1000) $\mathrm{CS} / \mathrm{ml}$, sin embargo los análisis de octubre de 2019 a febrero de 2020 mostraron un aumento en el valor de CCS, resultando en un promedio de 576.2(x1000) $\mathrm{CS} / \mathrm{ml}$, resultando en una multa al productor de $\mathrm{R} \$ 0,06$ por litro. La multa reflejada em uma reducción del $5 \%$ em el monto final pagado por el litro de leche. Luego de la adopción de prácticas correctivas y preventivas, hubo uma reducción en el valor de CCS de la finca. Así, es posible concluir que la asistencia técnica es de suma importancia para asesorar al productor sobre el mejor desarrollo lechera, maximizando la rentabilidad económica de la propriedad.

Palabras clave: Agricultura familiar; Cría de ganado lechero; Calidad de la leche; Rentabilidad.

\section{Introdução}

O Brasil é um dos maiores produtores de leite e seus derivados do mundo, tendo atingido no ano de 2018 uma produção de aproximadamente 33,8 bilhões de litros, sendo o estado de Minas Gerais responsável por 26,4\% na participação nacional. O Norte de Minas Gerais apresenta grande produção de leite, tornando-se a região um dos polos de produção do país, mesmo com fatores que afetam a produtividade dos animais, como a baixa disponibilidade, o clima e a falta de mão de obra qualificada (Abiodun et al., 2021; Dias et al., 2021; Reis et al., 2021).

A ausência na higiene da ordenha e os elevados níveis de mastite nas propriedades são os principais causadores de prejuízos dentro da produção (Puerto et al., 2021; Dalanezi et al., 2020; Dolecheck et al., 2019). A necessidade na melhoria dos níveis de higiene e boas práticas de fabricação em fazendas produtoras de leite é algo exigido pelos sistemas federais e pelas indústrias beneficiadoras par a produção mais segura da matéria prima (Whitehead \& Lake, 2018).

A busca por critérios que favoreçam a produtividade dos animais associados a qualidade do leite é exigida pelo mercado interno e externo. Busca-se utilizar estratégias que garantam esta qualidade, como o baixo índice de contagem de células somáticas (CCS) e contagem bacteriana total (CBT), e altos valores de proteína e gordura (Reis et al., 2020). Relacionado a isto, um gerenciamento correto da propriedade com uma avaliação criteriosa dos custos é de suma importância dentro da atividade (Silva et al., 2019; Morais et al., 2020).

A qualidade do leite é um dos principais fatores que devem ser levados em consideração visto que grandes empresas atualmente buscam e pagam bonificações pela mesma, havendo lucros para o produtor quando as metas são atingidas (Monte et al., 2021; Vargas et al., 2019), aspectos microbiológicos como a contagem de células somáticas (CCS) e a contagem bacteriana total (CBT), além de parâmetros da composição do leite, principalmente o teor de proteína e gordura.

Além da composição química, a qualidade microbiológica do leite é de extrema importância na produção de derivados lácteos. Neste contexto as células somáticas e a contagem total das bactérias contaminantes têm grande influência sobre as características organolépticas e sobre a durabilidade e tempo de prateleira dos produtos derivados (Silva, 2019).

O Programa Nacional de Melhoria da Qualidade do Leite (PNQL), estipulado pelo Ministério da Agricultura, Pecuária e Abastecimento e as IN76 e 77/2018, determinam que o produtor atenda padrões mínimos de qualidade do leite tanto em sua composição química quanto em aspectos sanitários, havendo penalizações ou bonificações pelo comprimento da normativa. $\mathrm{O}$ objetivo deste estudo foi avaliar o efeito das penalizações ou bonificações referentes à contagem bacteriana total (CBT) e 
contagem de células somáticas (CCS) do leite sobre o valor final pago pelo litro de leite em propriedades no norte de Minas Gerais.

\section{Metodologia}

Para o desenvolvimento do presente estudo, foi adotada a metodologia de pesquisa em campo e natureza qualitativa, como descrito por Pereira et al., (2018). Foram realizadas visitas mensais com o propósito de levar assistência técnica a pequenos produtores de leite da região do Norte de Minas Gerais, orientando sobre o gerenciamento da atividade, solucionando problemas na cadeia produtiva e agregando conhecimento teórico e prático com o intuito de melhorar a rentabilidade da atividade. Os dados foram coletados em uma fazenda leiteria de agricultura familiar, localizada no distrito de Engenheiro Dolabella, Bocaiúva, MG.

O clima da região é classificado como tropical úmido, com verão seco de acordo com a classificação de Köppen (Alvares et al., 2014), marcada por uma estação seca de abril a outubro e um período de chuvas compreendido entre novembro e março. A propriedade possui 20 hectares e um plantel de 11 vacas leiterias mestiças (Holandesa x Gir).

Durante as visitas foram realizadas diferentes atividades, desde acompanhamento de ordenha, pesagem dos animais, planejamento de volumoso, assistência nutricional, acompanhamento reprodutivo, manejo da fase de cria e recria dentre outras atividades. Para a realização deste estudo foram coletados os dados mensais referentes aos valores de CBT e CCS obtidos após análise do leite pelo laticínio e as informações referentes ao valor pago por litro de leite, incluindo os valores relativos às bonificações ou penalizações referentes a qualidade do leite entregue entre os meses de outubro de 2019 a junho de 2020.

\section{Resultados e Discussão}

Dos 9 meses analisados, a propriedade não apresentou alterações sobre o valor de CBT, permanecendo com uma média geral de 7(x1000) UFC/ml (Gráfico 1), mantendo-se abaixo da média exigida pela IN 76 que permite um valor máximo de 300 (x1000) UFC/ml para essa variável, demonstrando que houve realização dos protocolos de limpeza e desinfecção de maneira correta. Os resultados obtidos diferem dos encontrados por Jamas et al., (2018), os quais avaliaram 13 propriedades da agricultura familiar e encontraram resultados com média de 1.292.000 demonstrando situação precária nas propriedades analisadas, pela ausência de práticas que diminuam o índice de CBT da propriedade.

Garcia et al., (2017) citam que os principais fatores que estão relacionados a contaminação e aumento dos índices de CBT nas propriedades são, ausência de utilização de produtos de limpeza e sanitização nos equipamentos de ordenha ou tanque de refrigeração, ausência de desinfecção dos tetos pré-ordenha, úberes contaminados por microrganismos e mastite (Oliveira et al., 2017; Callefe \& Langoni 2015).

$\mathrm{O}$ valor de CBT é influenciado diretamente pela temperatura e umidade do ambiente, procedimentos de ordenha e regulagem de equipamentos. Tais fatores podem afetar diretamente a composição nutricional do leite, uma vez que a proliferação bacteriana de forma desordenada pode causar alterações como degradação de proteínas, gorduras e carboidratos tornando o produto impróprio para o consumo e beneficiamento industrial (Paiva et al., 2012).

A produção total de leite nos meses citados foi de 41.921 litros, como o valor de CBT ficou abaixo do estipulado pelo laticínio, o produtor foi bonificado com $\mathrm{R} \$ 0,04$ por litro produzido, arrecadando no final do período um valor de $\mathrm{R} \$ 1.877,00$. A bonificação aos produtores é o principal incentivo realizado por laticínios visando melhorar a qualidade do leite, relacionados a CBT, CCS os quais são os principais parâmetros microbiológicos analisados (Monteiro Junior et al., 2021), sendo estes também indicativo da sanidade do rebanho (Dias et al., 2015).

A aplicabilidade de práticas de manejo que promovem melhorias na qualidade do leite reduzindo os teores de CBT e CCS apresentam potencial satisfatório sobre o aumento da renda na pecuária leiteira. Em trabalho desenvolvido por Pinheiro 
Teixeira Júnior et al., (2015), verificaram que a melhora na qualidade do leite foi seguida de um aumento na remuneração, promovendo um incremento ao valor pago por litro de leite, aumentando a rentabilidade da propriedade.

Os laticínios que buscam melhor qualidade de leite em propriedades, normalmente oferecem assistência técnica as propriedades, com intuito de aumentar a disseminação de informações, capacitação dos produtores e funcionários, fazendo com que haja melhor qualidade do leite produzido. Em estudo realizado por Monteiro Junior et al., (2021), observou-se que a maior parte dos produtores analisados (64,3\%), receberam bonificação pela qualidade do leite, estando estes resultados associados a características microbiológicas e composição, sendo considerado principalmente proteína e gordura.

O valor médio da CCS no período estudado foi de 464,3(x1000) CS/ml, entretanto as análises de outubro de 2019 à fevereiro de 2020 (55,5\%) apontaram aumento no valor CCS (Gráfico 1), resultando em uma média de 576,2(x1000) CS/ml, permanecendo fora dos padrões máximos exigidos pela IN 76 de $500(x 1000) \mathrm{CS} / \mathrm{ml}$. A produção total nestes 5 meses foi de 23.897 litros, havendo penalização ao produtor em $\mathrm{R} \$ 0,06$ por litro, ocasionando em perda final de $\mathrm{R} \$ 1.434,00$. A penalização refletiu em uma redução de $5 \%$ no valor final pago pelo litro de leite.

As médias de CCS obtidas nos meses de maio $(281 \times 1000 \mathrm{CS} / \mathrm{ml})$ e junho $(264 \times 1000 \mathrm{CS} / \mathrm{ml})$ foram as menores dentre os nove meses estudados (Gráfico 1), resultando um maior valor pago por litro de leite durante esses meses. Este resultado corrobora com o relatado por Dias et al. (2015) que ao avaliarem o efeito da sazonalidade dos componentes do leite sobre a cinética de pagamento por qualidade em vinte fazendas leiteiras localizadas na região sudoeste do estado de Goiás verificaram que os meses de maio e junho representaram os maiores percentuais de bonificações.

A averiguação dos teores de CCS é um importante fator para ser analisado a fim de avaliar a qualidade higiênica do leite, pois cada vez mais as indústrias alimentícias buscam um produto de qualidade superior para reduzir possíveis problemas de saúde pública. O valor demonstrado pela CCS é um parâmetro que está diretamente ligado a sanidade do aparelho mamário do rebanho e reflete na qualidade industrial do leite e seu rendimento na indústria (Dias et al., 2015). Santos \& Fonseca (2006) explicaram que os teores elevados de CCS refletem na qualidade organolépticas do leite e seus derivados, contribuindo intimamente para o rendimento industrial de lácteos bem como o tempo de prateleira desses produtos. Através do relatado acima é possível notar que a CCS é um critério de pagamento importante para avaliar o manejo sanitário dentro da propriedade com o intuito de adotar medidas de higiene e controle de mastite. 
Gráfico 1: Relação entre os valores de Contagem Bacteriana Total (CBT) E Contagem de Células Somáticas (CCS) e o valor final pago por litro de leite em propriedade rural da região norte de Minas Gerais.

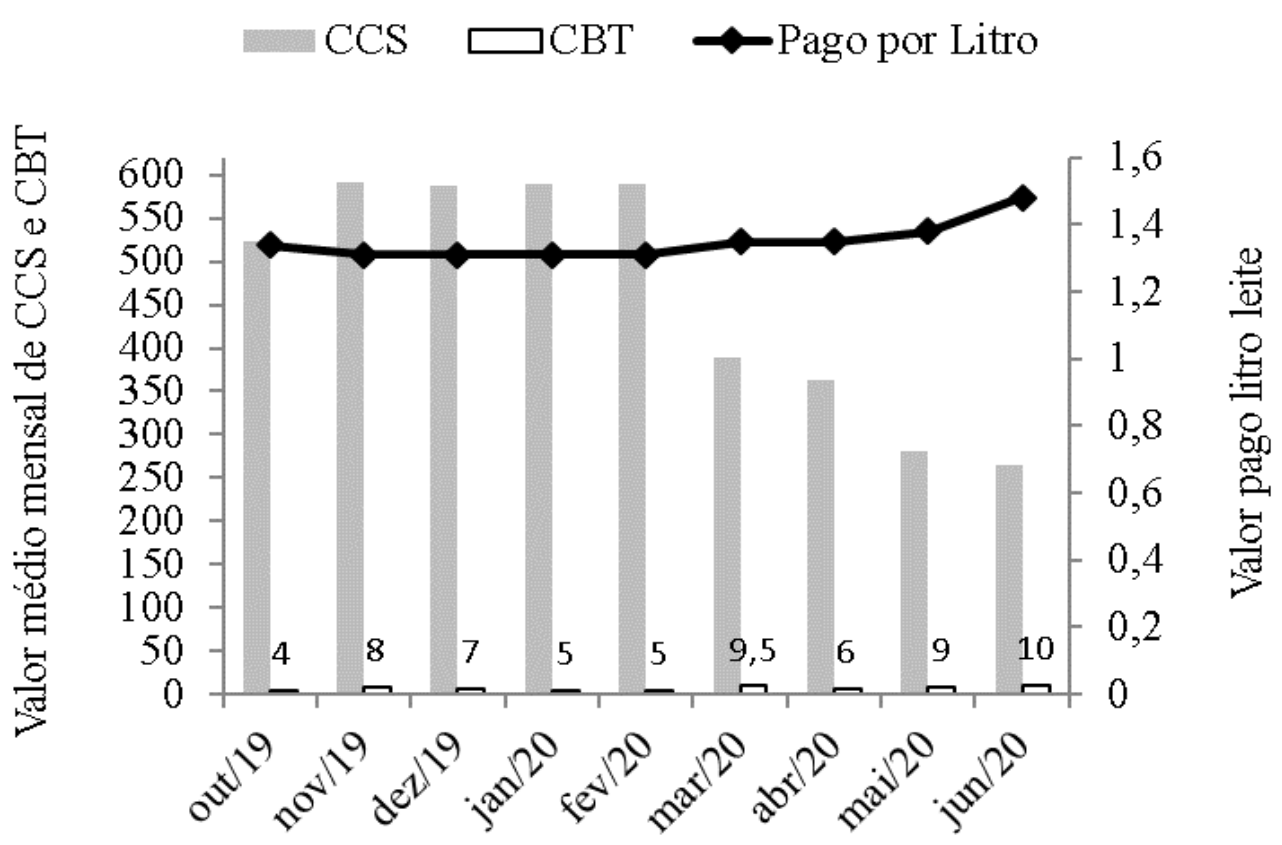

Fonte: Acervo autoral (2020).

Paixão et al., (2014), citam que uma das formas de garantir a bonificação dos produtores é diminuir os efeitos provocados pela ausência das boas práticas agropecuárias. A introdução de práticas que garantam a sanidade do rebanho proverá maior retorno aos produtores. Autores como Júnior et al., (2011) e Vallin et al., (2009) corroboram com o estudo de Paixão et al., (2014), pois observaram queda nos níveis de CCS dos rebanhos estudados após a inclusão de boas práticas agropecuárias dentro das propriedades.

A adoção de práticas como linha de ordenha contribui para melhorias na produção leiteira, pois Pimenta et al., (2020), citam que a utilização da linha de ordenha, com base no diagnóstico de mastite da propriedade, promove a separação das vacas no ato da ordenha, sendo que vacas primíparas e pluríparas que não foram contaminas por mastite são ordenhadas primeiro. Posteriormente, são ordenhadas vacas que testaram positivo para mastite, mas foram curadas, sendo feito a ordenha de vacas com mastite subclínica e posteriormente vacas com mastite clínica.

A realização do teste de caneca telada em todos os animais antes das ordenhas, realização correta do pré e pós dipping e direcionamento do leite de animais que testaram positivo no teste Califórnia Mastite Teste (CMT) para a alimentação dos bezerros, contribuíram para reduzir a taxa de leite com CCS alto no tanque de resfriamento, visto que foi possível observar redução de aproximadamente $56 \%$ no valor de CCS nos últimos meses, resultando em um ganho por bonificação dessa variável de aproximadamente $\mathrm{R} \$ 1.081,00$.

A adoção de boas práticas para produção leiteira visando atender as áreas de nutrição, bem-estar animal, higiene de ordenha e sanidade animal foram estabelecidas durante o período de assistência com o intuito de proporcionar melhorias garantindo uma matéria prima de qualidade, um rebanho saudável e um maior retorno econômico. Portanto, é importante salientar que a realização das atividades deve ser constante e progressiva para garantir um crescimento da propriedade. A adoção de pagamento por qualidade tem como o intuito incentivar e melhorar a qualidade do leite produzido, com isso fortalecer a parceria entre cooperados e cooperativas, que buscam estimular o pagamento focado na qualidade do produto sem 
se preocupar apenas com o volume produzido, fornecendo desta forma ao mercado consumidor um produto com uma maior segurança alimentar (Meneghatti et al., 2020).

\section{Conclusão}

Conclui-se que a assistência técnica realizada é de suma importância para assessorar o produtor e promover melhor desenvolvimento da atividade leiteira, contribuindo para solução de problemas, aumentando o retorno financeiro da propriedade e o fornecimento de um produto de origem animal seguro para o mercado consumidor.

Em futuros estudos, sugere-se que seja realizado o acompanhamento de um número maior de fazendas para validar e comprovar a importância da adoção de um acompanhamento técnico eficiente que incentive o produtor a entregar um produto com maior valor agregado e maior qualidade ao mercado consumidor.

\section{Referências}

Abiodun, A. O., Lakew, H., Tesfuhuney, W., \& Lombard, W. (2021). Influence of heat stress on milk production and its financiais implications in semi-arid areas of South Africa. Heliyon, 7(2), e06202. 10.1016/j.heliyon.2021.e06202.

Alvares, C. A., Stape, J. L., Sentelhas, P. C., Moraes Gonçalves, J. L., \& Sparovek, G. (2014). Köppen's climate classification map for Brazil. Meteorologische Zeitschrift, 22(6), 711-728. 10.1127/0941-2948/2013/0507.

Callefe, J. L. R., \& Langoni, H. (2015). Qualidade do leite: uma meta a ser atingida. Veterinária e Zootecnia. 22(2), 151-162.

Dalanezi, F. M., Joaquim, S. F., Guimarães, F. F., Guerra, S. T., Lopes, B. C., Schmidt, E. M. S., Cerri, R. L. A., \& Langoni, H. (2020). Influence of pathogens causing clinical mastitis on reproductive variables of dairy cows. Journal of Dairy Science, 103(4), 3648-3655. 10.3168/jds.2019-16841.

Dias, M., Assis, A. C. F., Nascimento, V. A., Saenz, E. A. C., \& Lima, L. A. (2015). Sazonalidade dos componentes do leite e o programa de pagamento por qualidade. ENCICLOPÉDIA BIOSFERA, Centro Científico Conhecer - 11: 2011713.

Dias, M. B. de C., Leão, K. M., Silva, M. A. P. da, Santos, K. S. R., Araújo Neto, F. R. d., Flávio Neto, J., Marques, T. C., \& Nicolau, E. S. (2021). Effect of shading in physiological responses, milk yield and quality of Girolando cows. Research, Society and Development, 10(1), e45410111986. 10.33448/rsdv10i1.11986.

Dolecheck, K. A., Gárcia-Guerra, A., \& Morães, L. E. (2019). Quantifying the effects of mastitis on the reproductive performance of dairy cows: A metaanalysis. Journal of Dairy Science, 102(9), 8454-8477. 10.3168/jds.2018-15127.

Espindola, W. R., Nascente, E. de P., Urzêda, M., Teodoro, J. V. da S., Gonçalves, G. B., CastrO, R. D., Martins, M. E. P., \& Souza, W. J. de. (2020). Quality of refrigerated raw milk produced in the microregion of Pires do Rio, Goiás, Brazil. Research, Society and Development, 9(7), e153973958. 10.33448/rsdv9i7.3958.

Garcia, F. A., Carvalho, V. S., Soares, N. R., \& FerreirA, S. M. (2017). Parâmetros de qualidade do leite cru fornecido para indústria de processamento de produtos lácteos. Colloquium Agrariae, 13(Especial), 372-380. 10.5747/ca.2017.v13.nesp.000241.

Instituto Brasileiro de Geografia e Estatística - IBGE. (2020). Indicadores IBGE: estatística da produção pecuária, 2020. Recuperado de: https://biblioteca.ibge.gov.br/index.php/biblioteca-catalogo?id=72380\&view=detalhes.

Jamas, L. T., Salina, A., Rossi, R., Menozzi, B. D., \& Langoni, H. (2018). Parâmetros de qualidade do leite bovino em propriedades de agricultura familiar. Pesquisa Veterinária Brasileira, 38(4). 10.1590/1678-5150-PVB-5372.

Júnior B. R. C. L., Oliveira, P. M., Martins, M. L., Pinto, C. L. O., Martins, E. M. F., \& Souza, G. H. (2011). Aplicação das boas práticas agropecuárias no processo de ordenha em uma propriedade rural do município de Rio Pomba, Minas Gerais. Revista do Instituto de Laticínios "CândidoTostes”, $380,31-39$.

Meneghatti, M. R., Griebeler, A., Farina, L. O., \& Bertolini, G. R. F. Impactos do sistema de pagamento por qualidade do leite em uma cooperativa da agricultura familiar. Desenvolvimento Regional em debate. 10, 1203-1234, 2020. 10.24302/drd.v10i0.2963.

Monte, A. M., Sousa, A. W. B. de, Ramos, L. de S. N., Cunha, L. S., Lima, L. R. do N., Diniz, H. da S., Negreiros, I. F. L., \& Moreira Filho, M. A. (2021). Somatic cell counts in refrigerated raw milk from individual producers through rapid methods. Research, Society and Development, 10(6), e2210615160. $10.33448 /$ rsd-v10i6.15160.

Monteiro Junior, C. S., Bankuti, F. I., Martinelli, R. R., Lima, P. G. L., Mendonça, B. S., \& Santos, M. G. R. (2021). Incentives and typology of dairy production systems that participate in programs to improve milk quality. Revista em Agronegócio e Meio Ambiente, 14(3), e7774. 10.17765/2176$9168.2021 \mathrm{v} 14 \mathrm{n} 4 \mathrm{e} 7774$.

Morais, S. B., Orlandi, C. M. B., Gasparotto, P. H. G., Filho, J. V. D., Cavali, J., Campeiro Junior, L. D., \& Daudt, C. (2020). Costs and Benefits of Artificial Insemination on Small Dairy Properties. Revista Agrarian. 13(48), 249-264. 10.30612/agrarian.v13i48.10652. 
Oliveira, N. C., Vieira, M. L., Santos, W. B. R., Camargos, A. S., Ribeiro, J. C., Cezário, A. S., Oliveira, E. M. O., \& Valente, T. N. P. (2017). Contagem de células somáticas, contagem bacteriana total e análises físico-químicas do leite produzido na região sul do estado de Goiás. Colloquium Agrariae, 13(Especial 2), 135-141. 10.5747/ca.2017.v13.nesp2.000219.

Paiva, C. A. V., Cerqueira, M. M. O. P., Souza, M. R. S., \& Lana, A. M. Q. (2012). Annual evolution of raw milk quality processed in a dairy industry of Minas Gerais state, Brazil. Arquivo Brasileiro de Medicina Veterinária e Zootecnia, 64(2), 471-479. 10.1590/S0102-09352012000200030.

Pereira, A. S., Shitsuka, D. M., Parreira, F. J., Shitsuka, R. (2018). Metodologia da pesquisa científica. [e-book]. Santa Maria. Ed. UAB/NTE/UFSM. Recuperado em 10 de novembro de 2021.

Pimenta, J. L. A., Maia, A. M., Morães, A. D., Fonseca, J. S., Costa, M. J. R. P., \& Gigena, M. C. (2020). Influência da linha de ordenha no comportamento de vacas leiteiras. Revista Científica Rural, 22(1), 1-9. 10.30945/rcr-v22i1.3140.

Pinheiro Teixeira Júnior, F. E., Lopes, M. A., \& Ruas, J. R. M. (2015). Efeito do pagamento por qualidade do leite na rentabilidade da atividade leiteira. Revista do Instituto de Laticínios, 70(1), 1-11. 10.14295/2238-6416.v70i1.375.

Puerto, M. A., Shepley, E., Cue, R. I., Warner, D., Dubuc, J., \& Vasseur, E. (2021). The hidden cost of disease: I. Impact of the first incidence of mastitis on production and economic indicators of primiparous dairy cows. Journal of Dairy Science, 104(7), 7932-7943. 10.3168/jds.2020-19584.

Reis, E. M. B., Vieira, J. A., Lopes, M. A., Demeu, F. A., Bruhn, F. R. P., Vicente, F. H., Pereira, A. B., \& Filho, L. M. S. (2020). Diagnóstico de propriedades leiteiras e fatores associados à qualidade higiênico sanitária do leite. PUBVET, 14(2), 1-15. 10.31533/pubvet.v14n2a508.1-15.

Reis, L. de S., Marques, L. R., Santos, S. N., Paim, T. do P., Guimarães, T. P., Marques, T. C., \& Leão, K. M. (2021). Milk production in silvipastoril system: Review. Research, Society and Development, [S. 1.], 10(4), e26810414043. 10.33448/rsd-v10i4.14043.

Santos, M.V., \& Fonseca, L.F.L. (2006). Estratégias para controle de mastite e melhoria da qualidade do leite. 1ed. Barueri: Editora Manole. 314p.

Silva, H. K. D. (2019). Programas de Pagamento por Qualidade (PPQ): eficiência da adoção por indústrias lácteas brasileiras (Doctoral dissertation, Universidade de São Paulo).

Silva, M. F., Silva, A. C., Rezende, A. C., \& Pinto, R. S. (2018). Avaliação zootécnica e econômica de propriedades leiteiras: foco na gestão de custos. Custos $e$ @gronegócio on line, 14(Edição Especial), 1-31.

Vallin, V. M., Beloti, V., Battaglini, A. P. P., Tamanini, R., Fagnani, R. Angela, H. L., \& Silva, L. C. C. (2009). Melhoria da qualidade do leite a partir da implantação de boas práticas de higiene na ordenha em 19 municípios da região central do Paraná. Semina: Ciências Agrárias, 30(1), $181-188$.

Vargas, D. P., Nornberg, J. L., Scheibler, R. B., Rizzo, F. A., Ritt, L. A., \& Milani, M. P. (2019). Physical-chemical and microbiological quality of bovine milk in different production systems and seasons. Ciência Animal Brasileira, 20, 1-11, e-46898, 10.1590/1809-6891v20e-46898. 